\title{
Bovine Abortions Associated with Neospora in Denmark
}

During recent years protozoa of the Neospora genus have been identified as a major cause of bovine abortions world wide (Barr et al. 1991, McIntosh \& Haines 1994, Thornton et al. 1991, Yaeger et al. 1994). A presumptive diagnosis of Neospora abortion can be made on the foetal histopathology as infected foetuses have a distinctive pattern of multifocal necrotizing and non-suppurative encephalitis often with an accompanying nonsuppurative myocarditis and a varying degree of focal inflammation in other organs (Barr et al. 1990, Thornton et al. 1991). However, confirming the diagnosis of Neospora abortion requires detection of protozoa in foetal tissues that react positively by immunohistochemistry with Neospora specific antisera (Barr et al. 1990, 1991).

In routine diagnostic examinations of aborted bovine foetuses in Denmark, lesions presumptive of Neospora infections are commonly found, but a specific diagnosis has not been established. Therefore, a minor investigation which included immunohistochemical examination of paraffin embedded tissues was performed on 2 suspected cases of Neospora abortion.

This article presents the findings from the cases and reports for the first time bovine abortions caused by the bovine Neospora parasite in Denmark.

Bovine foetuses with the corresponding placenta and maternal blood were submitted for routine diagnostic evaluation to the Danish Veterinary Laboratory from 2 dairy herds where multiple abortions had occurred. Microbiologic examinations of foetal tissues and fluids as well as serology on foetal pleural effusion and maternal blood were performed as previously decribed (Agerholm et al., accepted) and were negative for viral or bacterial pathogens. Tissues collected for histology included foetal brain, lung, myocardium, liver, kidney, and placenta. The tissues were fixed in $10 \%$ buffered neutral formalin, paraffin embedded, sliced, and stained with haematoxylin and eosin. Based on the microscopic lesions found, a presumptive diagnosis of protozoal infection was made in each case. Tissues were sent to the California Veterinary Diagnostic Laboratory System, University of California for Neospora and Toxoplasma gondii immunohistochemistry. Neospora and $T$. gondii antisera were both developed in rabbits using respectively, a bovine Neospora isolate (BPA1, optimal dilution 1:200) (Conrad et al. 1993) and combined ME-49 plus RH strains of $T$. gondii (optimal dilution 1:250).

Case 1. The aborted foetus originated from a Holstein-Friesian herd in which 6 abortions had occurred within a few weeks. The foetus was approximately 7 months old. Gross lesions were not present, but microscopically there was a mild multifocal encephalitis char- 


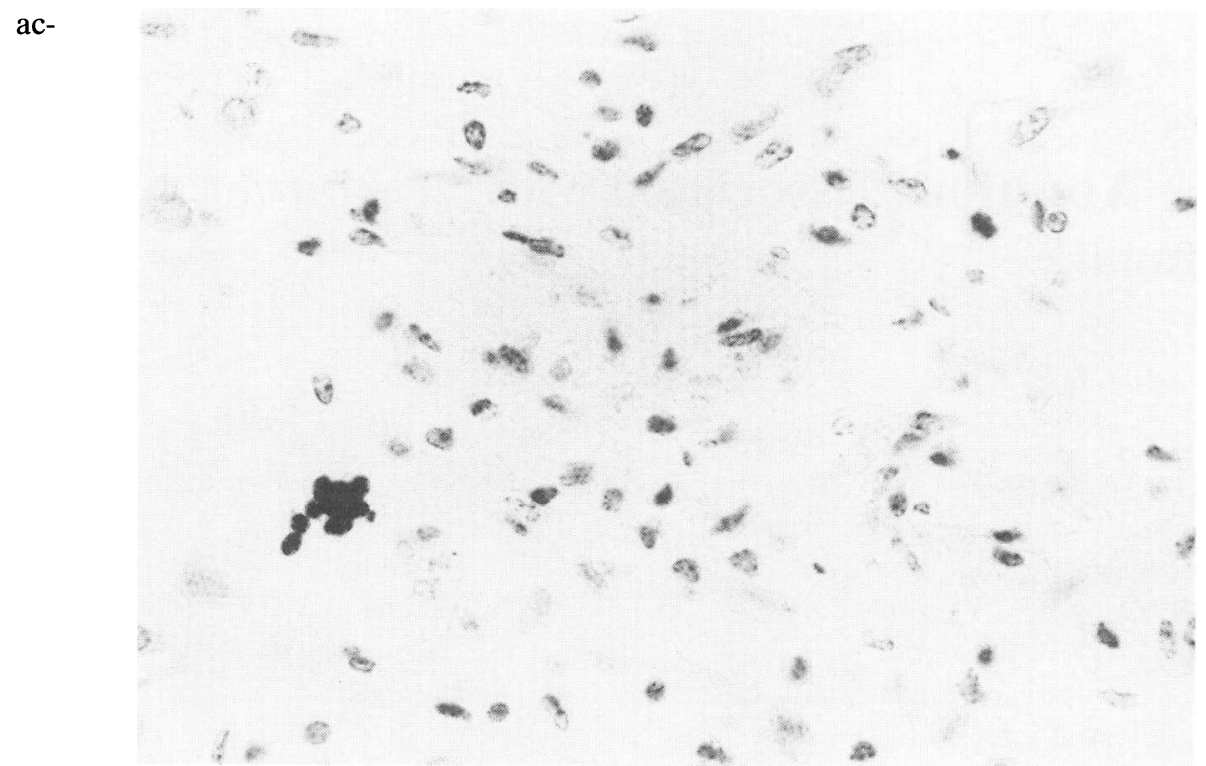

Figure 1. Photomicrograph of foetal brain from case No. 1. A cluster of tachyzoites staining positively with Neospora antiserum lies adjacent to a focus of gliosis. Immunoperoxidase, haematoxylin counterstain. $290 \mathrm{x}$.

terized by small random foci of gliosis. In addition, a focal necrotizing placentitis was found. By immunohistochemistry rare tachyzoites were found in association with foci of gliosis (Fig. 1) which reacted positively with Neospora antisera but failed to react with $T$. gondii antisera.

Case 2. The foetus was 5 months old and originated from a Holstein-Friesian herd in which 40 abortions had occurred during the last 2 years. Gross lesions were not present, but multifocal necrotizing encephalitis with gliosis, diffuse nonsuppurative myocarditis, and multifocal necrotizing hepatitis were found histologically. Immunohistochemical examination revealed the presence of protozoal tissue cysts and tachyzoites in the brain (Fig. 2) which reacted with the antisera as in case 1 . The histopathological changes found in cases 1 and 2 are in accordance with other reports
(Barr et al. 1990, Thornton et al. 1991), and as Neospora tachyzoites or cysts were demonstrated by immunohistochemistry, there is strong evidence that these abortions were caused by a Neospora species. These abortions represent the first reported cases of $\mathrm{NeO}$ spora infection in bovine foetuses in Denmark. It was not possible to determine whether all the abortions reported in the actual herds were due to Neospora. However, Neospora is well confirmed to be as a cause of multiple abortions (Anderson et al. 1991, Yaeger et al. 1994).

Even though the examined materials were very restricted, the findings suggest that $\mathrm{NeO}$ spora infections may be a common cause of bovine abortions in Denmark. However, conclusions on the incidence and prevalence of the infection in Danish cattle must await further studies. 


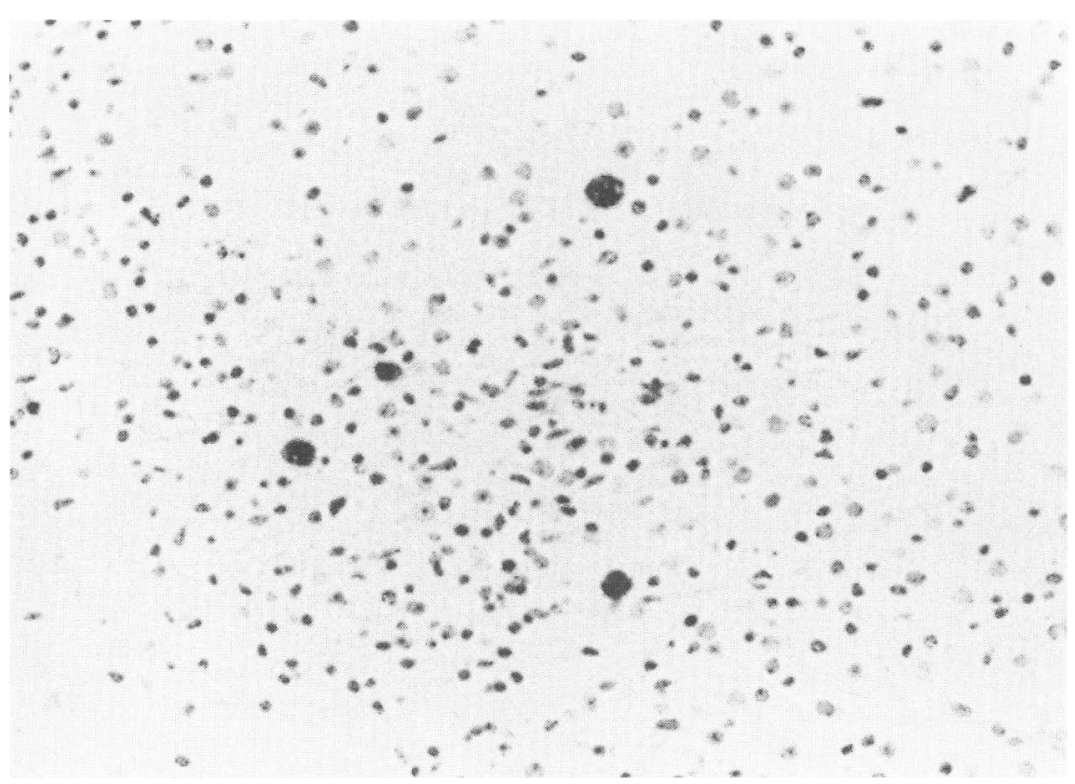

Figure 2. Photomicrograph of foetal brain from case No. 2. Several protozoal tissue cysts staining positively with Neospora antiserum lie around a focus of gliosis. Immunoperoxidase, haematoxylin counterstain. $140 \mathrm{x}$.

\section{Acknowledgements}

We wish to thank John Barbano for technical expertise in performing the immunohistochemistry.

\section{J.S. Agerholm}

Danish Veterinary Laboratory

Department of Pathology and Epidemiology

Copenhagen, Denmark.

\section{B.C. Barr}

California Veterinary Diagnostic Laboratory System University of California

School of Veterinary Medicine

Davis, California, USA.

\section{References}

Agerholm JS, Krogh HV, Jensen NE: A retrospective study on bovine abortions associated with Bacillus licheniformis. J. Vet. Med. B. (accepted).

Anderson ML, Blanchard PC, Barr BC, Dubey JP, Hoffman RL, Conrad PA: Neospora-like proto- zoal infections as a major cause of abortion in California dairy cattle. J. Amer. vet. med. Assoc. 1991, 198, 241-244.

Barr BC, Anderson ML, Blanchard PC, Daft BM, Kinde H, Conrad PA: Bovine fetal encephalitis and myocarditis associated with protozoal infections. Vet. Pathol. 1990, 27, 354-361.

Barr BC, Anderson ML, Dubey JP, Conrad PA: Neospora-like protozoal infections associated with bovine abortions. Vet. Pathol. 1991, 28, 110116.

Barr BC, Rowe JD, Sverlow KW, BonDurant RH, Ardans AA, Oliver MN, Conrad PA: Experimental reproduction of bovine foetal Neospora infection and death with a bovine Neospora isolate. J. Vet. Diagn. Invest. 1994, 6, 207-215.

Conrad PA, Barr BC, Sverlow KW, Anderson M, Daft B, Kinde H, Dubey JP, Munson L, Ardans $A$ : In vitro isolation and characterization of a Neospora sp. from aborted bovine foetuses. Parasitol. 1993, 106, 239-249.

McIntosh DW, Haines DM: Neospora infection in an aborted fetus in British Columbia. Can. Vet. J. 1994, 35, 114-115. 
Thornton RN, Thompson EJ, Dubey JP: Neospora abortion in New Zealand cattle. N. Z. Vet. J. $1991,39,129-133$.
Yaeger MJ, Shawd-Wessels S, Leslie-Steen P: Neospora abortion storm in a midwestern dairy. J. Vet. Diagn. Invest. 1994, 6, 506-508.

(Received November 18, 1994; accepted November 28, 1994).

Reprints may be requested from: J.S. Agerholm, Danish Veterinary Laboratory, Department of Pathology and Epidemiology, Bülowsvej 27, DK-1790 Copenhagen V, Denmark. 